\title{
Study of The Influence of Relay Elements on The Erosion Process on The Basis of Gis Technology
}

\author{
Hajiyev TA*1 and Aliyev $\mathrm{ZH}^{2}$ \\ ${ }^{1}$ West Caspian University,Azerbaijan,Baku-2020 \\ ${ }^{2}$ Institute of Soil Science and Agrochemistry ANAS \\ *Corresponding author: Hajiyev TA, West Caspian University, Azerbaijan, Baku
}

\section{ARTICLE INFO}

Received: 唪 June 25, 2020

Published: 峯 July 01, 2020

Citation: Hajiyev TA, Aliyev ZH. Study of The Influence of Relay Elements on The Erosion Process on The Basis of Gis Technology. Biomed J Sci \& Tech Res 28(4)2020. BJSTR. MS.ID.004680.

\section{ABSTRACT}

\begin{abstract}
Annotation
Erosion has become widespread in the local climatic conditions of Azerbaijan. From this point of view, different types of erosion (washing, erosion, deflation, etc.) can often be found in many soil types formed in the territory of the republic. It should be taken into account that as a result of erosion, the top fertile layer of the soil is washed away and as a result, the soil is deprived of the humus layer. In the presented article, the effect of relief elements on the erosion processes occurring in the lands of Gadabay region was studied on the basis of GIS technologies.
\end{abstract}

Keywords: Exposition; Slope Slope; Electronic Map; Landscape; Relief; Raster Palette

\section{Introduction}

The more eroded the soil, the more its non-eroded type, its granulometric, physical and chemical composition, water, air, thermal regime, bioecological properties, etc. will differ sharply in terms of indicators. To place the obtained information on electronic maps, it is enough to refer to the software "GIS", which is the most modern and convenient tool, which will help us to process dynamic information of any shape and size [1-3]. Through this program, we have the opportunity to both analyze and visualize the mechanisms of interaction of complex complexes that are closely interrelated in nature. At the same time, the system itself allows us to make a comprehensive analysis of natural and anthropogenic processes occurring in nature and in various sectors of the economy, as well as to identify global factors that contribute to these processes. One of the basic functions of the Geographic Information System is the design and construction of the database.

The first step in designing a database is to identify and refine the information we need. At this stage, the information is sorted so that it can be easily identified and entered into the database in the form of raster or vector layers. The quality of the analysis results depends on the quality of the data entered directly into the database. The main role here is played by the appropriate selection of the final information raw material. Information-bearing media that can be the final raw material are mainly field measurements, GPS coordinate data of field support points, satellite images of the area (Landsat 2, 8) and cartographic data (land maps, topographic, geological, etc.). The final data can be of different projections and sizes. The low accuracy of the final data results in less information being obtained and a higher accuracy layer not being created. In order to avoid such a situation, it is necessary to have information about the accuracy of the base data, especially their dimensions.

The next step is to enter the final data into the database and create layers on the data. The method of data entry into the system depends on the type of final data. Then comes the next step, which is the process of processing data in the database. During this process, the final data is gathered together into a single projection. In any case, it is possible to change one projection to another, as well as transform data from raster format to vector or vice versa [4]. 


\section{Research Object and Methodology}

The object of research was mountain-brown and mountain-black soils formed in different views of the northern slope of the northern part of the Lesser Caucasus. The degree of soil erosion at the object of study was determined on the basis of the comparative geographical methodology proposed by KA Alakbarov, and the determination of morphogenetic features by SHG Hasanov.

\section{Analysis of Results}

The high altitude and slope of the slopes create favorable conditions for erosion processes. The creation of a DEM (Digital Elevation Model) model of the area with the help of GIS technologies combines the following procedures [5] (Figure 1).

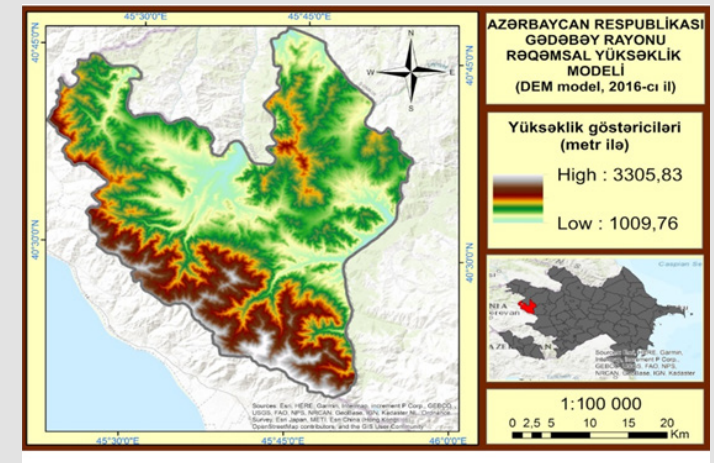

Figure 1: DEM model of Gadabay region.

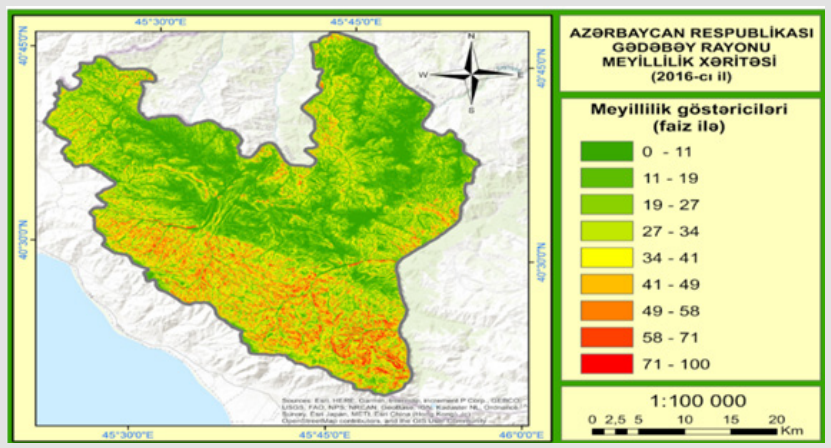

Figure 2: Inclination map of Gadabay region.

The first stage includes scanning of topographic maps and geographical closure in the coordinate system, digitization of the map, creation of altitude and isolation vector layers, electronic design of topographic maps at a scale of 1: 100,000. With the help of the DEM model, it is very quick and easy to create a map of exposure and slope rates based on GIS technologies (Figure 2). 0020Different characteristics of the slope of the relief of the area where the soil layer is formed are widely used in geographical research. One of the main morphometric indicators of Gadabay region is shown on the map of inclination rates. As shown in the figure, the red parts indicate steeper slopes, slopes with a slope of more than $27-34^{\circ}$ belong to the category of very steep slopes. The green parts indicate relatively flat areas. As the slope of the area decreases, the relief becomes flat, and as the slope increases, the slope stiffness increases.

In mountainous areas, the slope of the slopes is $27^{\circ}$ and more, which causes landslides. The slope of the slopes and the direction of elongation affect the direction of runoff, the density of vegetation, soil moisture and temperature. Therefore, these factors are one of the main causes of landslides. Slope stiffness analysis using ArcCIS version 10.3 showed that the average slope stiffness in the mountainous areas of the study area is 27-34 degrees. The main component of landscape formation is the slope of the topographic layer. Many areas of the region are formed between 1000-2000m altitudes (Figure 3).Clearly, this factor creates sufficient fertile conditions for the formation of moisture, as well as soil and vegetation. Spatial analysis of the slope slope directly confirms their connection with the geo-lithological and morphostructural structure of the area. Active landslides are more pronounced on slopes at altitudes of 1000-2000 m. This is due to the lithological composition of the rocks that make up these slopes and the high amount of atmospheric sediment [6-8]. One of the main morphometric indicators of slopes is the exposure. It characterizes the degree of solar energy supply of the slopes. Exposure is measured clockwise, passing a full circle from 0 degrees to 360 degrees. Each color indicates the degree of illumination of the area on the map (Figure 4).

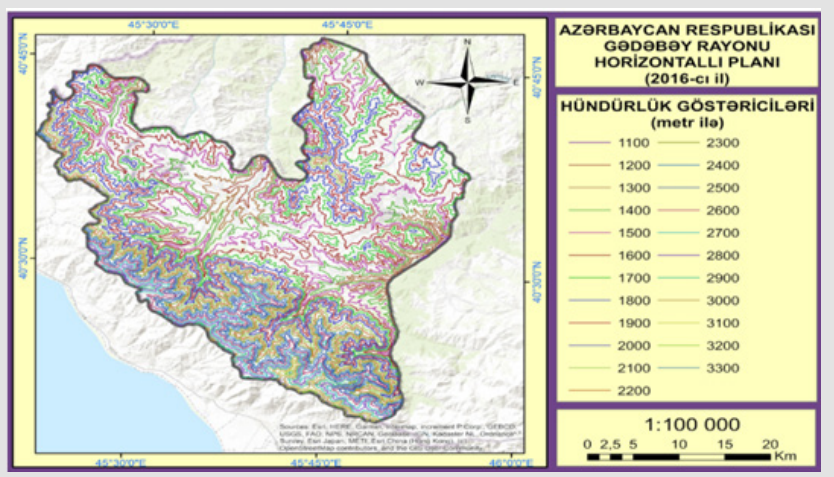

Figure 3: Horizontal plan of Gadabay region.
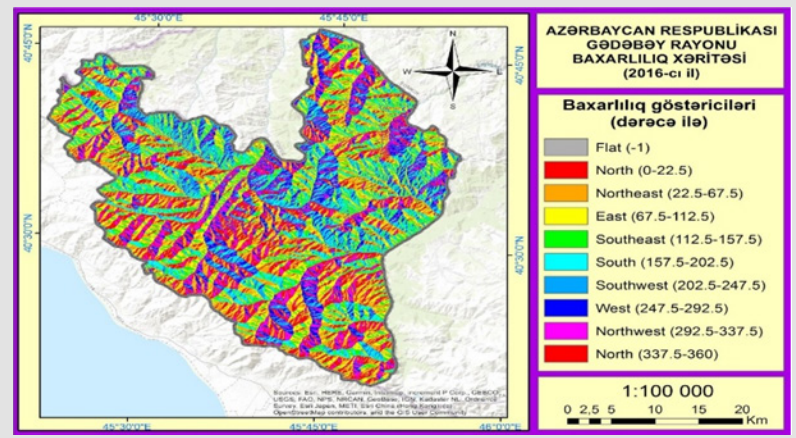

Figure 4: Map of Gadabay region. 
The southern slopes are represented by shades of green and blue, the northern slopes by red and pink, the western slopes by blue, and the eastern slopes by yellow. Gray color indicates a relatively smooth surface. Depending on the total duration of the sun's rays, the exposure of the slopes is divided into the following types:

a) Cold in the range of $0^{\circ}-22.5^{\circ}$ to $337.5^{\circ}-360^{\circ}$;

b) Moderate cold in the range of $22.5^{\circ}-67.5^{\circ}$ to $292.5^{\circ}$ $-337.5^{\circ}$;

c) Warm in the range of $67.5^{\circ}-112.5^{\circ}$ to $157.5^{\circ}-202.5^{\circ}$;

d) Medium heat in the range of $112.5^{\circ}-157.5^{\circ}$ to $202.5^{\circ}$ $-247.5^{\circ}$.

From the digital version of the solar exposure of the slopes, a quantitative assessment of the different lighting of the slopes is given. The value of each cell in the exposition network indicates the direction of inclination. Since there is no direction of smooth descents, it takes the value-1. The exposition map of the slopes compiled in electronic format allows to analyze the spatial regularity of the lighting of the region. This makes it easier for us to assess the conditions under which the landscape is formed in terms of heat supply. The first approach reflected the proportional duration of direct exposure to the sun's rays. The processing of the obtained data allows to compare the fields, to find the regularity of spatial expansion on them. Each field selected on the digital map is numbered sequentially.The parts are then grouped according to the main types.

According to the exposition, the slope is divided into two types - cold and hot. The transitions are treated as moderately cold and moderately warm.Cold and moderately cold slopes predominate. While landslides and denudation processes predominate on the northern slopes, the southern slopes are dominated by surface and linear erosion processes. Due to the sparse vegetation of the south-

ISSN: 2574-1241

DOI: $10.26717 /$ BJSTR.2020.28.004680

Hajiyev TA. Biomed J Sci \& Tech Res CC) This work is licensed under Creative

Submission Link: https://biomedres.us/submit-manuscript.php ern slopes, which are well warmed by the sun's rays, the soil layer can partially preserve its structural composition without being completely washed away by atmospheric sediments.

\section{Result}

As a result of field and chamber surveys conducted in 20142016, it was determined that brown mountain-forest soils are formed on slopes with an inclination of $11 \%$, and other soils with an inclination of $11 \%$ (on a relatively smooth part of the relief). A small part of the study area is soil resistant to leaching (hazard grade I $-6.5 \%$ of the total area). Medium-grade II hazardous soils make up $11.6 \%$ of the total area, and low-grade III hazardous soils make up $9.0 \%$ of the total area.

\section{References}

1. Aliyev AH, Mikayilova HH (2008) Natural conditions of Azerbaijan and the development of the erosion process, measures to combat it. ADPU Publishing House Baku pp. 148.

2. Alekperov KA (1980) Soil-erosion zone and land protection. Moscow p: 10-12.

3. Aliev ZH (2006) Scientific Validity of Approaches to Solving a Number of Agricultural Problems in Azerbaijan // International Engineering Journal 7(1): 7-13.

4. Antonov BA (1959) Little Caucasus. In: kn "Geomorphology of Azerbaijan” Izd-vo AN Azerb. USSR, Baku pp. 213.

5. Ibrahimov AA (1998) Adverse effects of soil erosion on the ecological situation in Azerbaijan and ways to prevent it (study of the problem of efficient use of eroded lands and irrigation of agricultural crops in Azerbaijan). Works of the Institute of Erosion and Irrigation. Volume II, Baku pp: 40-43.

6. Museyibov MA (1998) Physical geography of Azerbaijan. Maarif Publishing House, Baku pp: 400.

7. Ostrovsky J, Safarli S (2010) The use of GIS software in the study of soil erosion in Azerbaijan and the definition of the conditions of their protection. Educational materials. Poland pp: 117.

8. Соловей T (2012) Spatial analysis with the use of geoinformation systems tools Textbook. Poland p: 95.

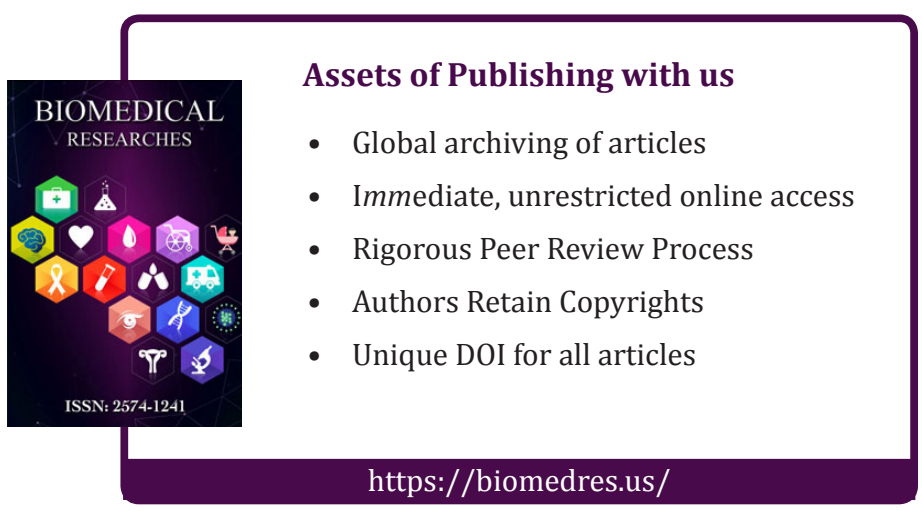

